\title{
Identification of prohibitin as a potential biomarker for colorectal carcinoma based on proteomics technology
}

\author{
DEBO CHEN ${ }^{1,3^{*}}$, FENGLIN CHEN $^{2 *}$, XINGRONG LU $^{1}$, XIAOSONG YANG ${ }^{1}$, \\ ZHONGBIN XU ${ }^{1}$, JIE PAN ${ }^{1}$, YING HUANG ${ }^{1}$, HUIMING LIN $^{1}$ and PAN CHI ${ }^{1}$ \\ Departments of ${ }^{1}$ General Surgery and ${ }^{2}$ Gastroenterology, Affiliated Union Hospital of General Surgery, \\ Fujian Medical University, Fuzhou 350001; ${ }^{3}$ Department of Surgery, First Hospital, \\ Quanzhou 362000, Fujian Province, P.R. China
}

Received February 25, 2010; Accepted April 13, 2010

DOI: 10.3892/ijo_00000684

\begin{abstract}
Differential protein expression was analyzed in carcinoma tissue to determine the correlation between protein levels and the clinical and pathological parameters of patients with colorectal carcinomas (CRC). Two-dimensional electrophoresis (2-DE) revealed 40 protein spots that were differentially expressed at two or greater fold difference in CRC that were identified by matrix-assisted laser desorption/ionization time of flight mass spectrometry (MALDI-TOF/TOF MS). Among these proteins, prohibitin (PHB) was found to be overexpressed in CRC. It was selected for Western blot and immunohistochemistry assay in subsequent tissue microassays (TMA). Thirty-five distinct proteins were differentially expressed at least 2-fold among normal and CRC tissues. The expression of 17 proteins, including PHB, was increased by $>2$-fold in CRC tissues $(\mathrm{p}<0.01)$. Immunohistochemistry and Western blot assays found that PHB was overexpressed in CRC cases, and the expression was higher than adenoma and normal tissues $(p<0.01)$, whereas there was no significant difference in expression of PHB between adenoma and normal tissues. Immunohistochemistry also suggested a link between PHB expression and poor differentiation $(\mathrm{p}<0.01)$. However, there was no difference in UICC stage, or location of CRC. Survival analysis suggested no significant correlation between PHB expression and poor prognosis. In summary, the over-
\end{abstract}

Correspondence to: Dr Pan Chi, Department of General Surgery, Affiliated Union Hospital, Fujian Medical University, Xinquan Rd. no. 29, Fuzhou 350001, Fujian Province, P.R. China

E-mail: cp3169@mail.fjmu.edu.cn

${ }^{*}$ Contributed equally

Abbreviations: 2-DE, two-dimensional electrophoresis; CRC, colorectal carcinoma; PHB, prohibitin; TMA, tissue microassay; MS, mass spectrometry; MALDI-TOF, matrix-assisted laser desorption-ionization-time of fight; UICC, International Union against Cancer

Key words: colorectal carcinoma, proteomics, prohibitin, biomarker, tissue microassay expression of PHB might be associated with the transformation process from adenoma to CRC. Further, it is a potential diagnostic and differentiation biomarker of CRC in the clinic.

\section{Introduction}

Colorectal cancer (CRC) is one of the most common gastrointestinal malignancies in the world. Almost one million new cases and 492,000 related death occur annually (1). Although several screening techniques, such as colonoscopy, fecal occult blood testing (FOBT), and analysis of various serial markers are recommended, the early diagnosis rate of CRC is still comparatively low. Tumor specific protein identification in CRC may provide novel biomarkers for assessing the central molecules that govern carcinogenesis of CRC, as well as benefiting early diagnosis of CRC patients. Recent application of proteomics techniques identified some new proteins that were up-regulated in CRC. It suggested that these up-regulated proteins may be potential biomarkers for diagnosis or therapeutics targets for treatment of CRC (2-4).

PHB is an evolutionarily conserved and ubiquitous protein that may be involved in tumorigenesis and development of CRC. Previous studies proposed PHB was a suppressor gene in tumor development (5-8). Immunocytochemistry staining has shown PHB to be up-regulated in some tumors or tumor cells $(9,10)$. However, the biological function of this protein is still unclear. PHB protein is overexpressed in CRC tissues compared with non-cancer tissue by two-dimensional gel electrophoresis $(11,12)$. Additional large sample, clinical studies are needed to determine the role of PHB in tumorigenesis and development of CRC before PHB can be used as a biomarker for disease based solely on proteomics.

In the present study comparative proteomics was used to identify the proteins that are highly expressed in CRC compared to normal mucosa. The results revealed a significant increase in PHB in specimens from patients with CRC. To clarify the role of PHB in CRC, we employed immunohistochemistry and Western blotting to determine the level of PHB in CRC tissue. Survival analysis was also performed to assay the correlation between PHB expression and patient survival. 


\section{Materials and methods}

Main reagents. All chemical reagents for 2-DE, Immobiline Drystrip pH 4-7 non-linear (NL), 24-cm IPG strips, and 2-D Quant Kit was purchased from Amersham Bioscience (Piscataway, NJ, USA). BCA Protein Quant Kit was provided by the Beyotime Institute of Biotechnology (Haimen, JiangSu, China) and the RIPA protein lysis buffer for Western blotting was from Pierce Company (Rockford, IL, USA). Mouse antihuman monoclonal prohibitin antibody (no. ab55618) was from ABCAM Biotechnology (Cambridge, UK). Anti-ßtubulin (no. D-10) antibody and HRP-conjugated anti-mouse IgG were purchased from Santa Cruz Biotechnology (Santa Cruz, CA, USA).

Clinical data and collection of specimens. All 12 cases of CRC and corresponding normal mucosa tissues $(>10-\mathrm{cm}$ away from the edge of the tumor tissue) were obtained after resection in our hospital. The tissues were placed in liquid nitrogen immediately and stored at $-80^{\circ} \mathrm{C}$ for use. The clinical and pathological characteristics of the recruited patients are listed in Table I. In the present study all the patients read and signed informed consents and this study was approved by the Ethics Committee of Union Hospital of FuZhou.

Paraffin-embedded tissue from 187 cases with sporadic $\mathrm{CRC}$ in stage I-III were probed for PBH protein expression. One hundred and fifty cases with nomal mucosa were also chosen from the 187 cases. These patients had undergone colorectal resection between January 2000 and June 2004, and they did not have distant metastasis nor had they received routine anticancer treatment. Sixty-two cases of colorectal adenoma tissue with low-grade dysplasia were selected for immunohistochemistry analysis using tissue microarray. The data from these patients are shown in Table II. After colorectal resection, follow-up was performed for up to 114 months. Survival time was recorded and the cumulative survival rate of the CRC patients was compared.

Protein extraction. The tissue samples were completely dissolved in lysis buffer containing $7 \mathrm{~mol} / \mathrm{l}$ urea, $2 \mathrm{~mol} / \mathrm{l}$ thiourea, and $4 \%$ CHAPS (w/v). They were centrifuged at $40,000 \mathrm{x} \mathrm{g}$ for $1 \mathrm{~h}$ and then the supernatants harvested. The concentration of the total protein was determined using a 2-DE Quant Kit in accordance with the manufacturer's instructions.

2-DE analysis of PHB protein in CRC tissue. Protein samples $(600 \mu \mathrm{g})$ from 12 cases of CRC and corresponding normal mucosa tissues were diluted in a $450-\mu 1$ rehydrated solution containing $7 \mathrm{~mol} / \mathrm{l}$ urea, $4 \%$ CHAPS, $2 \mathrm{~mol} / \mathrm{l}$ thiourea, $0.2 \%$ dithiothreitol (DTT), and 1\% pharmalyte $\mathrm{pH}$ 4.0-7.0 neutral lipid (NL) for one-dimensional (1-D) separation. Samples were loaded on 24-cm immobilized $\mathrm{pH}$ gradient (IPG) strips with an NL (pH 4-7) for isoelectric focusing (IEF) for $16 \mathrm{~h}$. The IEF phase was conducted for a total of $96 \mathrm{kV} / \mathrm{h}$ for analysis and preparation using an IPGphor instrument (GE Healthcare, Amersham Biosciences). The focused gels were equilibrated with Buffer-1, $6 \mathrm{~mol} / 1$ urea, $30 \%$ glycerol, $2 \%$ SDS, and $1 \%$ DTT, for 15 min followed by Buffer-2, only
DTT replaced with $2.5 \%$ iodoacetamide (IAA), for another $15 \mathrm{~min}$. Focused proteins were subsequently separated by $12.5 \%$ sodium dodecyl sulfate polyacrylamide gel electrophoresis (SDS-PAGE) for 2-DE assay. The gel was stained with CBB R350 overnight. By running the identical sample twice, the system reproducibility were examined to ensure the accuracy of analyses.

The stained gels were scanned and imaged, and the differentially expressed protein spots were analyzed and confirmed using Imaging Master 2D analysis software. Two or more fold increased or decreased protein spots in the tumor sample than in the normal tissue were chosen for further characterization by MALDI-TOF/TOF MS.

Identification of differentially expressed protein spots by MALDI-TOF/TOF MS. Differential protein spots were completely removed and destained before trypsin digestion. Tryptic peptides were extracted and MALDI-TOF/TOF MS analysis was performed in accordance with the methods of $\mathrm{Li}$ et al (13) using an ABI 4700 TOF-TOF Proteomics Analyzer at $355 \mathrm{~nm}$. The scanning range of the mass was from 700 to $3,200 \mathrm{Da}$, and the maximized mass resolution was at 1,500 Da. To calibrate the mass instrument, a trypsin digest of myoglobin was used for internal calibration. Protein identification was finished using the GPS Explorer software (Applied Biosystems) and MASCOT search engine (Matrix Science, London, UK). The following parameters were set in the search: human species, protein molecular mass that ranged from 700 to 3,200 Da, trypsin digest with one missing cleavage, MS/MS tolerance of $0.6 \mathrm{Da}$, peptide tolerance of $0.2 \mathrm{Da}$, and possible oxidation of methionine.

Western blot analysis. Protein concentrations from 12 samples of CRC and matched normal mucosa tissue samples were measured using the BCA Protein Quant Kit in accordance with the manufacturer's instructions. The gel was loaded with $25 \mu \mathrm{g}$ of protein for separation by SDS-PAGE for the Western blot assay (14). The proteins were transferred onto a sheet of polyvinylidene fluoride (PVDF) membrane with wet transfer $100 \mathrm{v}$ for $1.5 \mathrm{~h}$. The membrane was probed with a primary monocolonal mouse anti-human PHB antibody $(1: 1000)$ overnight at $4^{\circ} \mathrm{C}$. The membrane was washed three times with Tris-buffered saline (TBS) for 5 min each, and secondary sheep anti-mouse $\operatorname{IgG}$ (1:2000) was added. The membrane was washed once with TBS for another $5 \mathrm{~min}$. before being stained by an enhanced chemiluminescence (ECL) reagent (Pierce, USA) and imaged on X-ray film by autoradiography. Anti- $\beta$-tubulin was used as a control. The band intensity was measured by ImageQuant TL v2003.03 analysis software (Amersham, Bioscience), and the relative protein level of PHB was expressed as the ratio between the PHB and B-tubulin densities.

Tissue microarray and immunohistochemistry assay. The paraffin blocks of tissue from 187 cases of CRC, stages I-III, including 150 normal mucosa, and 62 colorectal adenomas were used to construct CRC tissue microarrays. Tissue core samples $1 \mathrm{~mm}$ in diameter were taken from representative areas of the CRC tissue samples. The microarrays consisted of a second core of tumor tissue, one core of matched normal 
Table I. Clinical features of patients with colorectal cancer.

\begin{tabular}{rrrlccc}
\hline No. & Sample no. & Age & Sex & Location $^{\mathrm{a}}$ & Differentation stage & TNM stage \\
\hline 1 & 3 & 56 & Male & $\mathrm{S}$ & Moderate & $\mathrm{T} 2, \mathrm{~N} 0, \mathrm{Mx}$ \\
2 & 7 & 52 & Male & $\mathrm{R}$ & Moderate & $\mathrm{T} 4, \mathrm{~N} 1, \mathrm{Mx}$ \\
3 & 8 & 78 & Female & $\mathrm{S}$ & Moderate & $\mathrm{T} 3, \mathrm{~N} 0, \mathrm{Mx}$ \\
4 & 13 & 84 & Male & $\mathrm{Ce}$ & Moderate & $\mathrm{T} 4, \mathrm{~N} 0, \mathrm{Mx}$ \\
5 & 16 & 85 & Male & $\mathrm{R}$ & Moderate & $\mathrm{T} 3, \mathrm{~N} 2, \mathrm{M} 1$ \\
6 & 25 & 65 & Female & $\mathrm{S}$ & Moderate & $\mathrm{T} 3, \mathrm{~N} 0, \mathrm{Mx}$ \\
7 & 36 & 53 & Female & $\mathrm{R}$ & Moderate & $\mathrm{T} 3, \mathrm{~N} 2, \mathrm{M} 1$ \\
8 & 45 & 47 & Male & $\mathrm{S}$ & Moderate & $\mathrm{T} 4, \mathrm{~N} 2, \mathrm{Mx}$ \\
9 & 54 & 68 & Female & $\mathrm{R}$ & Moderate & $\mathrm{T} 2, \mathrm{~N} 0, \mathrm{Mx}$ \\
10 & 66 & 56 & Female & $\mathrm{S}$ & Moderate & $\mathrm{T} 4, \mathrm{~N} 2, \mathrm{M} 1$ \\
11 & 75 & 81 & Male & $\mathrm{D}$ & Moderate & $\mathrm{T} 3, \mathrm{~N} 1, \mathrm{M} 1$ \\
12 & 114 & 79 & Male & $\mathrm{S}$ & Moderate & $\mathrm{T} 2, \mathrm{~N} 0, \mathrm{Mx}$ \\
\hline
\end{tabular}

aS, sigmoid colon; R, rectum; D, decending colon; Ce, cecum.

Table II. Clinical features of all human tissue samples.

\begin{tabular}{ll}
\hline Clinical features & No.
\end{tabular}

$59.03 \pm 12.51(24-81)$ $90 / 60$

150

\section{Adenoma \\ Mean age (range) (years) \\ Gender (male/female)}

$56.35 \pm 14.13(13-81)$ $46 / 16$

\section{CRC}

Mean age (range) (years)

Gender (male/female)

$58.81 \pm 12.90(24-81)$

$115 / 72$

Location

$\begin{array}{ll}\text { Proximal colon } & 31(16.6 \%) \\ \text { Distal colon } & 41(21.9 \%) \\ \text { Rectum } & 115(61.5 \%)\end{array}$

UICC stage

I

II

$27(14.4 \%)$

$79(42.2 \%)$

III

$81(43.4 \%)$

Differentiation grade

$\begin{array}{ll}\text { Well } & 51(27.3 \%) \\ \text { Moderate } & 104(55.6 \%) \\ \text { Poor } & 32(17.1 \%) \\ \text { Total } & 187\end{array}$

tissue, along with one core of adenoma tissue. The cores from the donor blocks were put into new paraffin blocks. Four $\mu \mathrm{m}$ thick sections were mounted on 3-amino-propyltriethoxysilane coated slides for subsequent staining with monoclonal mouse anti-human PHB antibody (1:100) using a two-step Envision method (Dako, Carpinteria, CA). Isotype control antibody was substituted for the primary antibody for the control slides. After hematoxylin counterstaining, immunostaining was scored by two independent pathologists. The discrepancy between the two reviewers was resolved by re-examination to achieve agreement.

Given the homogeneity of the target protein's staining, tumor specimens were scored in a semiquantitative manner using the following previously described scale $(15,16)$. Immunostaining intensity (i) was classified as: lack of staining (0), mild staining (1), moderate staining (2), and strong staining (3). The percentage of the stroma stainingpositive (ii) was semiquantitatively divided into five grades: $<5 \%$ (0), 6-25\% (1), 26-50\% (2), 51-75\% (3), and >75\% (4). The score for each section was measured as: (i) $\mathrm{x}$ (ii) $=$ section score and the result was defined as negative (- 0$)$, weakly positive $(+1-3)$, positive $(++4-7)$, and strongly positive $(+++8-12)$. A minimum of five fields from each section were evaluated.

Statistical analysis. All data are expressed as mean \pm standard deviation. The Wilcoxon two-sample test was used to compare the difference between two groups. The Spearman rank coefficient was employed to assay correlations between immunoreactivity and clinical parameters. Comparisons among multiple groups were performed by One-way analysis of variance (ANOVA), LSD t-test, or Dunnett t-test. Comparisons of ordinal data between two groups were analyzed by rank-sum test. The Kaplan-Meier method was used to assay survival probability, and the differences were assessed 


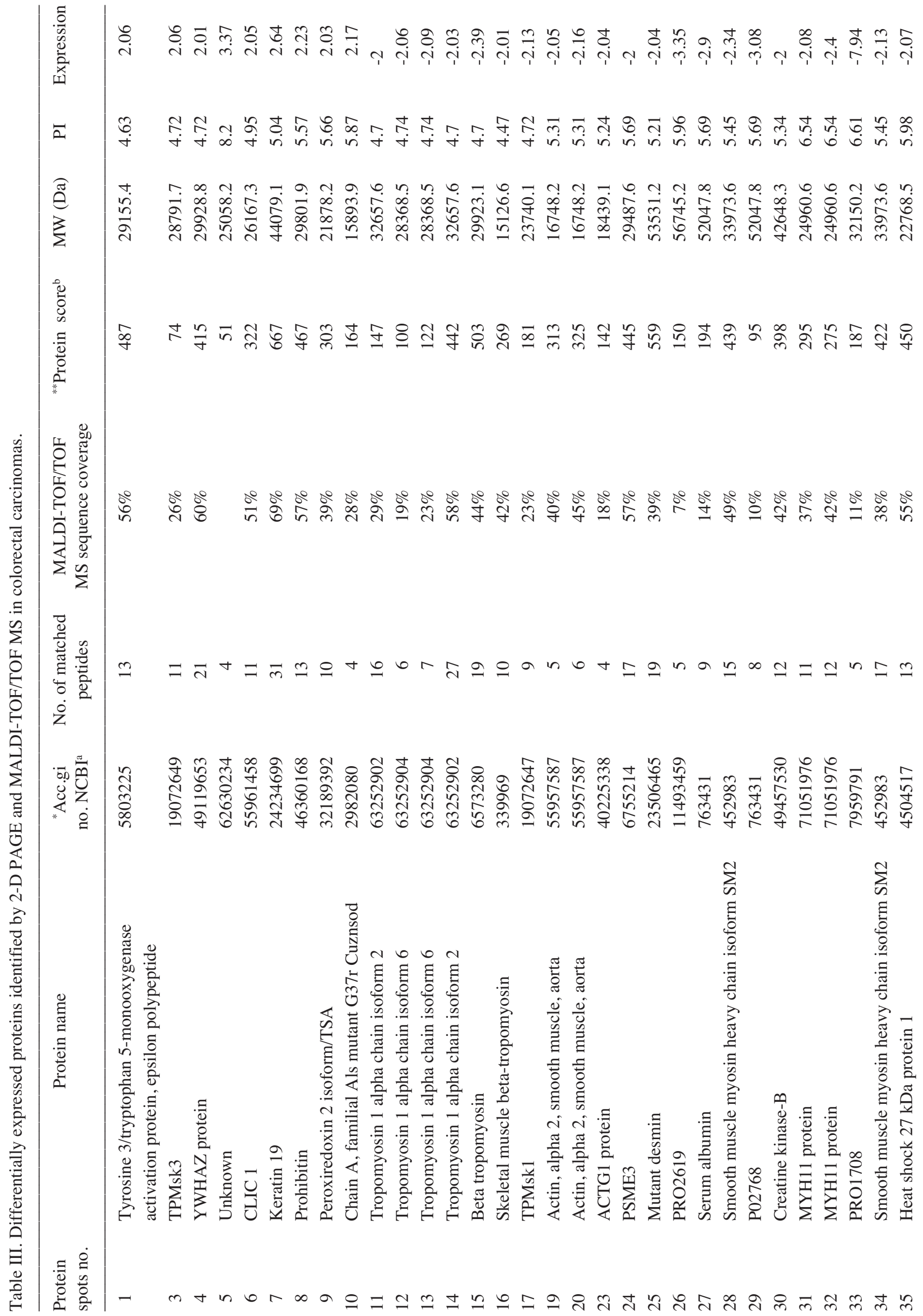




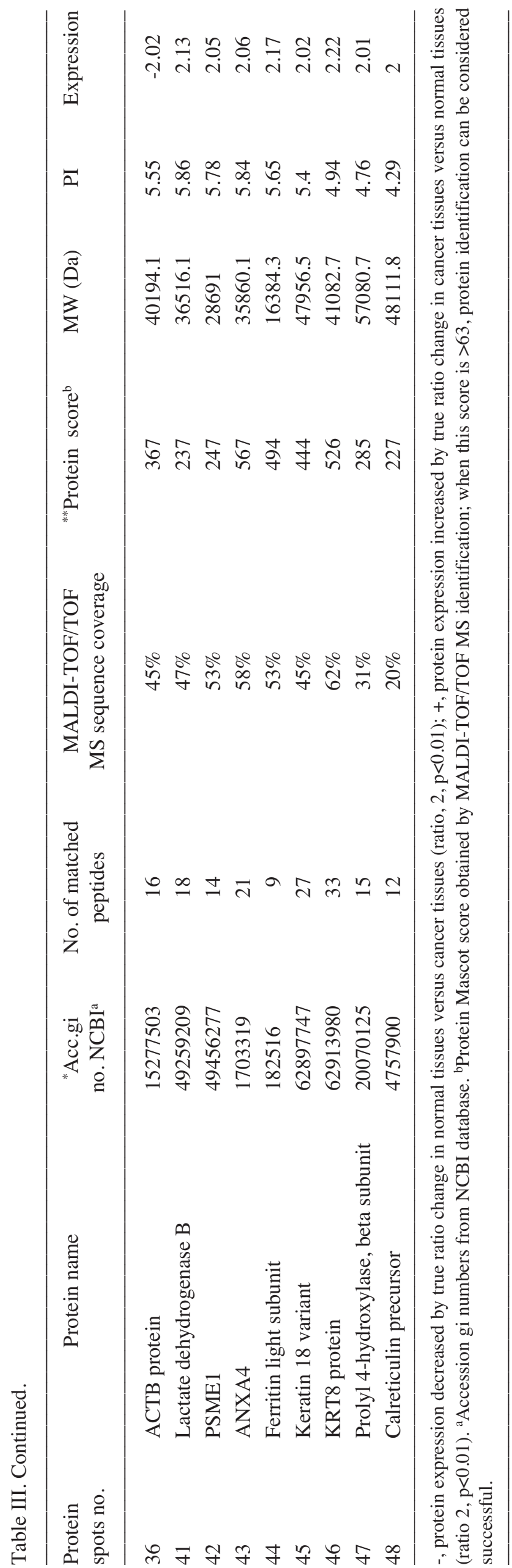

by the log-rank test. All the analyses were performed with SPSS13.0 software and a $\mathrm{p}<0.05$ was considered significant.

\section{Results}

2-DE analysis of CRC. CRC and adjacent normal colorectal tissues from 12 patients $(67 \pm 14$ years old) were analyzed in duplicate by $2-\mathrm{DE}$ and we detected $985 \pm 45$ and $1012 \pm 53$ protein spots ( $\mathrm{pH} 4.0-7.0$ ), respectively (Fig. 1). 2-D gels revealed that 40 protein spots were differentially expressed between $\mathrm{CRC}$ and normal colorectal tissues $(\mathrm{p}<0.05)$.

Mass spectrum identification of differentially expressed proteins. Thirty-five differentially expressed proteins were confirmed using MS/MS analysis. Among them, we found that 18 were more weakly expressed and 17 were overexpressed in the CRC samples (Table III and Fig. 1). After initial identification, we focused on the proteins that have not been well studied in primary CRC.

One protein spot that was significantly increased in CRC compared with normal colorectal tissue was identified as PHB (Fig. 2). The predicted molecular masses/pI value for prohibitin is $30 \mathrm{kDa} / 5.57$, fit well with the position of a spot on the 2-DE gel. MS/MS analysis confirmed PHB with a high MASCOT score of 467 and $57 \%$ sequence coverage (Table III and Fig. 3).

Validation of PHB by Western blot assay. Western blot analysis was performed to confirm the observations from 2-DE. The expression of PHB in 10 samples of CRC tissue (10/12, $83.33 \%$ ) was markedly increased compared with the normal tissues and with colorectal adenoma (Fig. 4).

Tissue microarray, clinicopathological, and immunohistochemical assay. In order to further verify and locate the expression of PHB in cancer tissues, 187 CRC tissue samples and 150 non-neoplastic tissues, and 62 cases of colorectal adenoma tissues were placed into three-tissue microarrays for examination by immunohistochemistry using a specific antibody against PHB. Staining for PHB was mainly located in the cytoplasm of CRC cells (Fig. 5A). In the 150 normal tissue specimens, we saw no staining in $10 \%$ and weak positive staining in $43.3 \%$ of the samples. Positive was seen in $38.7 \%$ and strongly positive staining in $8 \%$ of the normal specimens. In the 62 adenoma specimens we detected no staining in $1.6 \%$, weakly positive staining in $30.6 \%$, positive staining in $62.9 \%$ and strongly positive staining was detected in $4.8 \%$ of the samples. In 187 CRC specimens, we detected weakly positive staining in $4.8 \%$, positive staining in $38.5 \%$, and strongly positive staining in $56.7 \%$ of the samples.

The semiquantitative scoring of immunoreactivity for normal colon was 3.66 \pm 2.36 , adenoma $4.03 \pm 1.82$ and CRC for specimens $8.25 \pm 3.02$. The differences in the scores between the groups were significant (Table IV; $\mathrm{p}<0.01$ ). CRC specimens expressed more PHB than in the adenoma and normal colon tissue. Furthermore, PHB expression was significantly higher in $\mathrm{CRC}$ than in colorectal adenoma and normal tissues $(\mathrm{p}<0.001)$, whereas there was no significant difference in PHB expression between adenoma and normal tissue (Fig. 5B).

According to the histological differentiation of the 187 carcinoma samples, $27.3 \%$ were highly, $55.6 \%$ were 


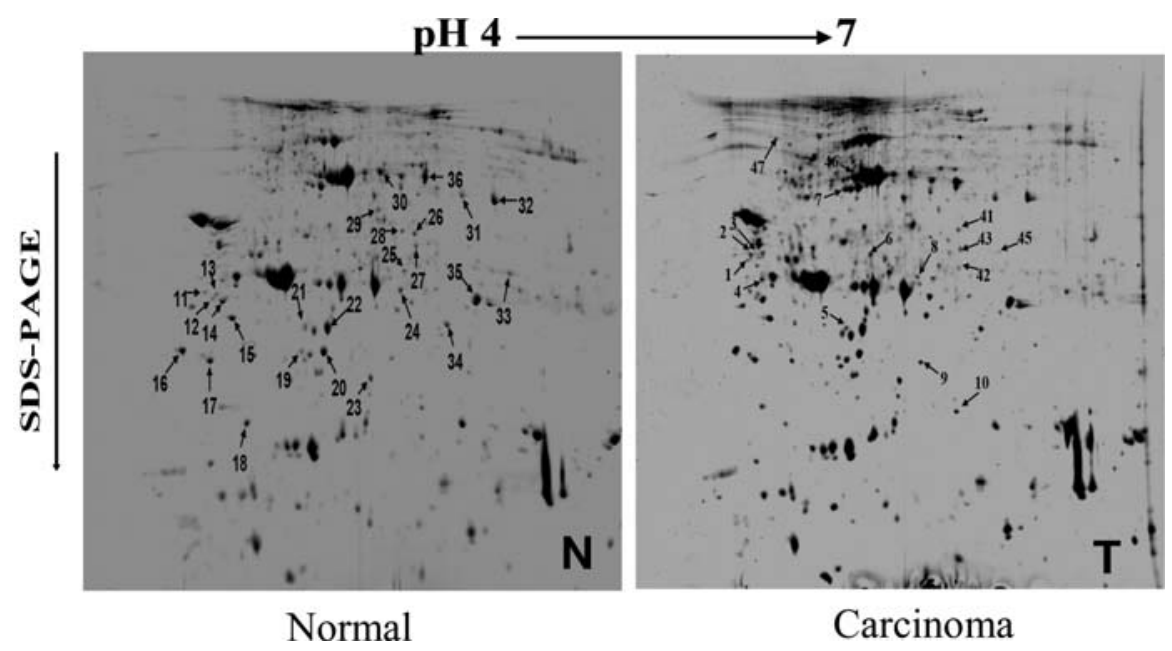

Figure 1. 2-DE assay of differential proteins in $\mathrm{CRC}$ and corresponding normal tissues. Whole cell lysate $(600 \mu \mathrm{g})$ from CRC (T) and normal (N) tissues was separated by 2-DE and visualized by Coomassie blue R350 staining. Arrows in the figure indicate identified protein spots that were significantly and consistently altered between carcinoma tissue and control normal tissues.

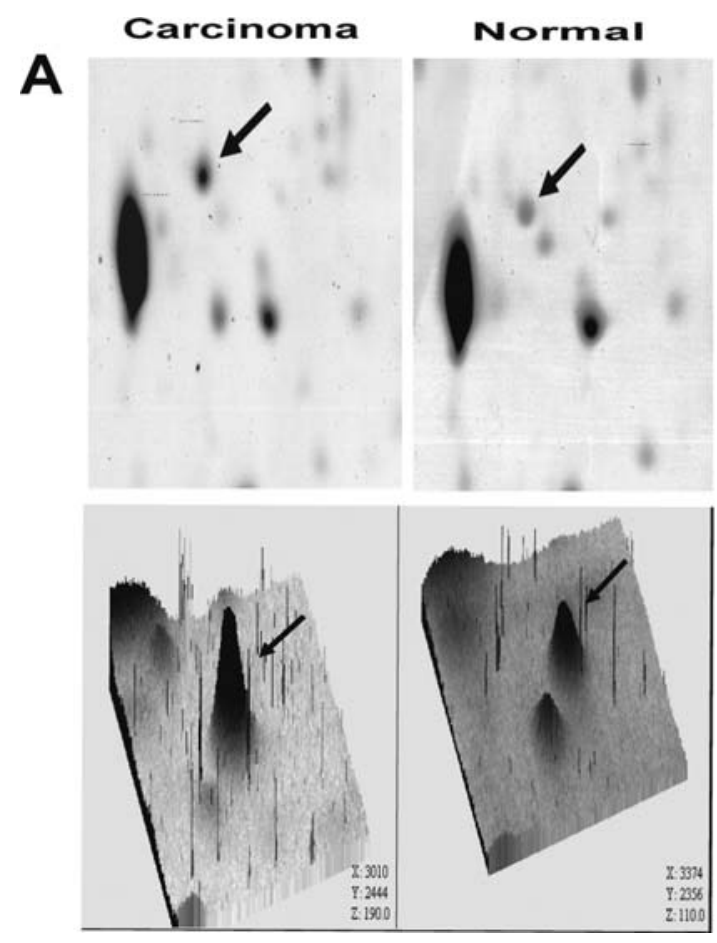

B

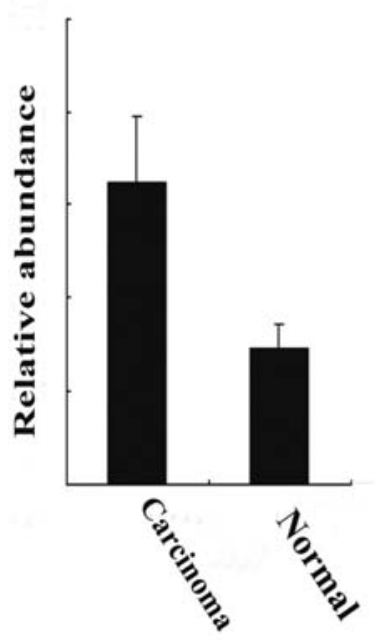

Figure 2. Validation of prohibitin (PHB) in CRC tissue relative to normal tissues. (A) 2-DE gel map of PHB in CRC tissues and corresponding normal tissues; arrows indicate PHB spots. Lower part, three-dimensional image of PHB expression by Imaging Master 2D 5.0 analytical software. (B) Chart indicating PHB expression in 2-DE.

moderately, and $17.1 \%$ were poorly differentiated. Overexpression of PHB was shown to be significantly more likely to present with poor differentiation $(\mathrm{p}<0.01)$ (Table V). The percentage in UICC stage I was $14.4 \%$, stage II was $42.2 \%$, and stage III was $43.4 \%$ according to the UICC staging criteria. The number of CRC specimens located in proximal colon was $16.5 \%$, in distal colon $22.0 \%$ and in the rectum $61.5 \%$. The expression of PHB was not significantly altered in UICC staging or locations of CRC (Tables VI and VII). In addition, survival analysis suggested no significant correlation between increased PHB expression and poor prognosis in CRC patients (Fig. 5C).

\section{Discussion}

Many interconnected signaling networks are involved in cellular regulation events at epigenetic, transcriptional, and translational levels. The intracellular signaling and gene transcription systems, as well as the protein pathways that connect the extracellular microenvironment to the 


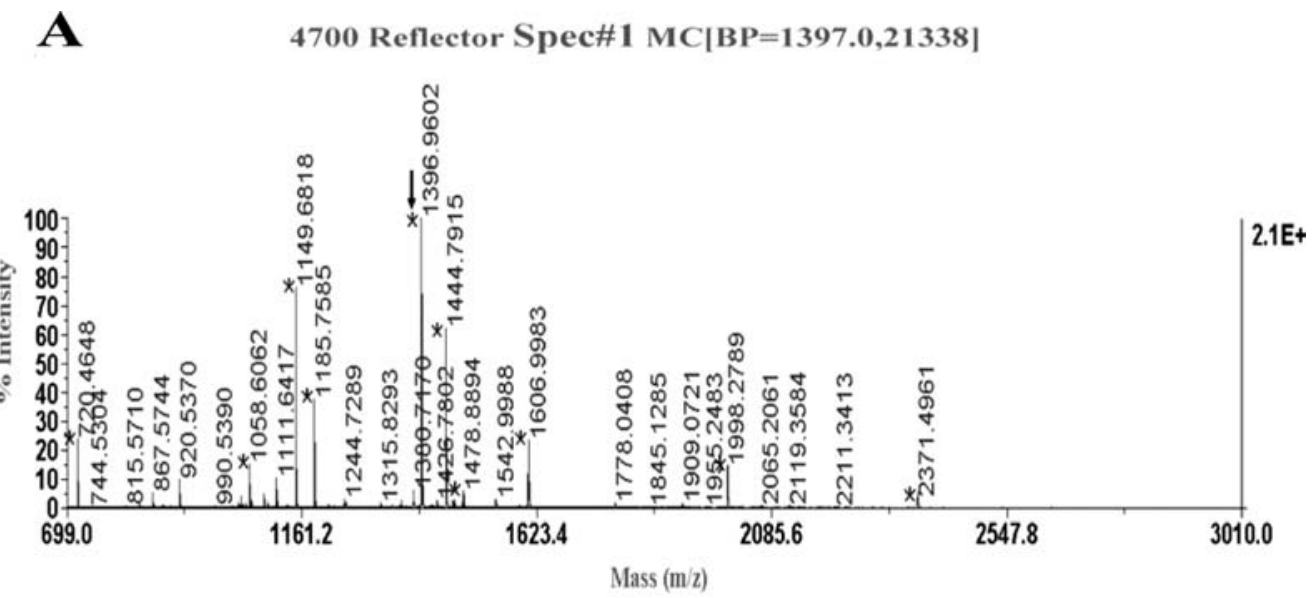

B

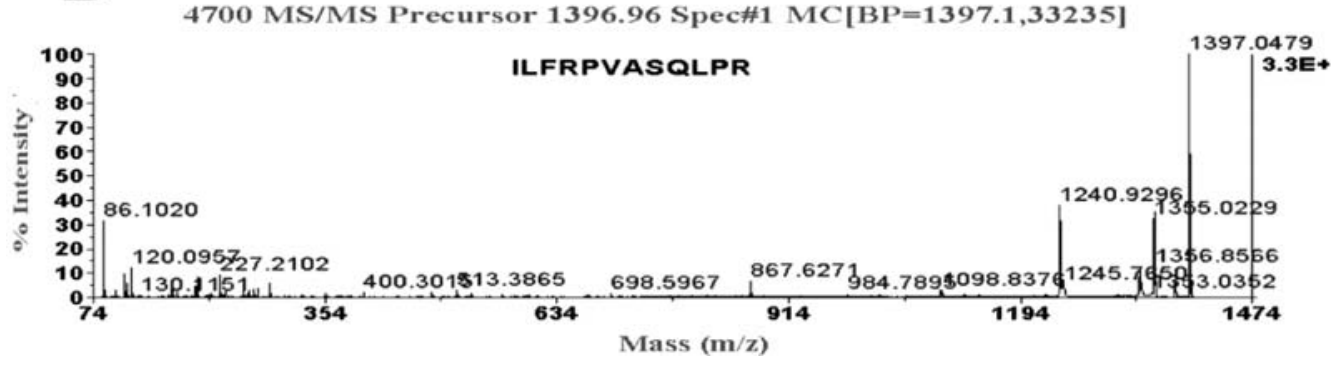

Figure 3. MALDI-TOF-MS spectra for differentially expressed proteins. (A) An example of the peptide mass map of PHB. Peptide signals corresponding to PHB are marked with asterisks. (B) MALDI-MS/MS sequencing of peptide 1396.96. The peptide sequence was identified as ILFRPVASQLPR, which led to the identification of PHB.

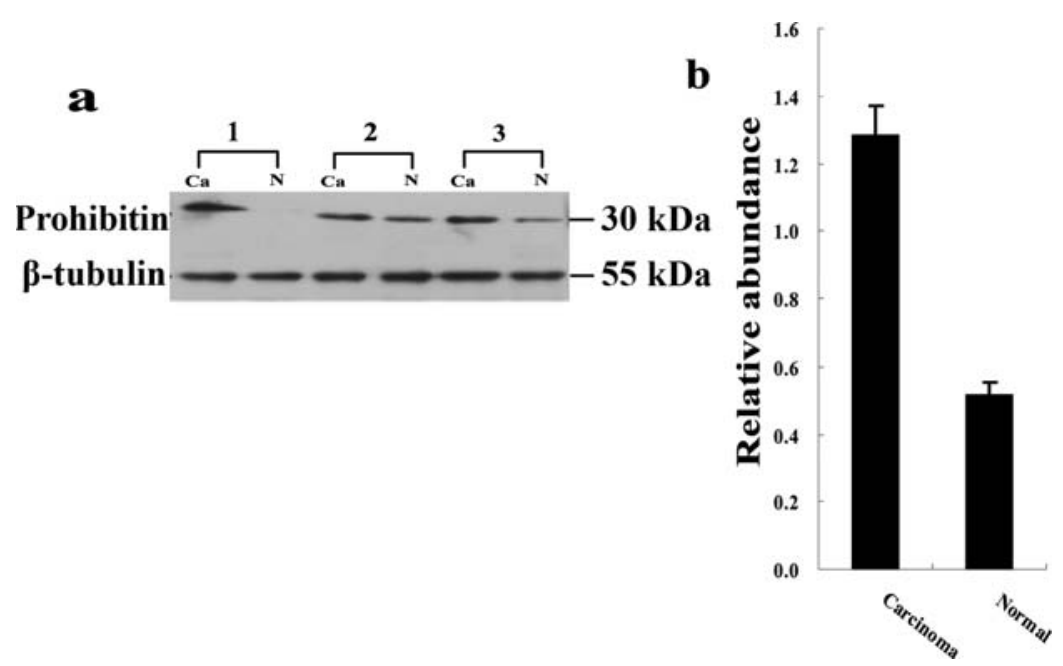

Figure 4. (a) Western blot assay of PHB protein in CRC and corresponding normal tissues. (b) Relative expression level of PHB in CRC and corresponding normal tissues.

Table IV. Prohibitin immunoreactivity in normal mucus, adenoma, and CRC.

\begin{tabular}{lrllllll}
\hline & Cases & \multicolumn{1}{c}{+} & \multicolumn{1}{c}{+} & ++ & $+_{+++^{\mathrm{a}}}$ & Average score $^{\mathrm{b}}$ \\
$\mathrm{N}$ & 150 & $10 \%(15 / 150)$ & $43.3 \%(65 / 150)$ & $38.7 \%(58 / 150)$ & $8.0 \%$ & $(12 / 150)$ & $3.66 \pm 2.36$ \\
$\mathrm{Ad}$ & 62 & $1.6 \%(1 / 62)$ & $30.6 \%(19 / 62)$ & $62.9 \%(39 / 62)$ & $4.8 \%$ & $(3 / 62)$ & $4.03 \pm 1.82$ \\
$\mathrm{Ca}$ & 187 & 0 & $4.8 \%(9 / 187)$ & $38.5 \%(72 / 187)$ & $56.7 \%(106 / 187)$ & $8.25 \pm 3.02$ \\
\hline
\end{tabular}

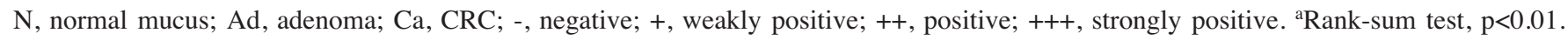
bone-way ANOVA analysis, $\mathrm{p}<0.01$. 
A

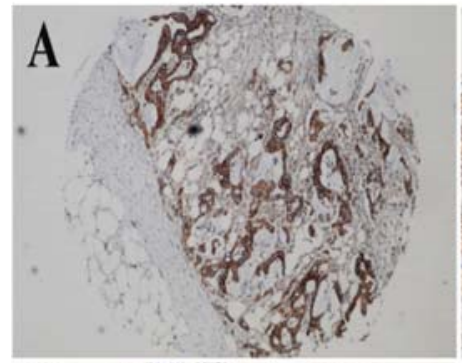

$\mathrm{C}_{000808}$
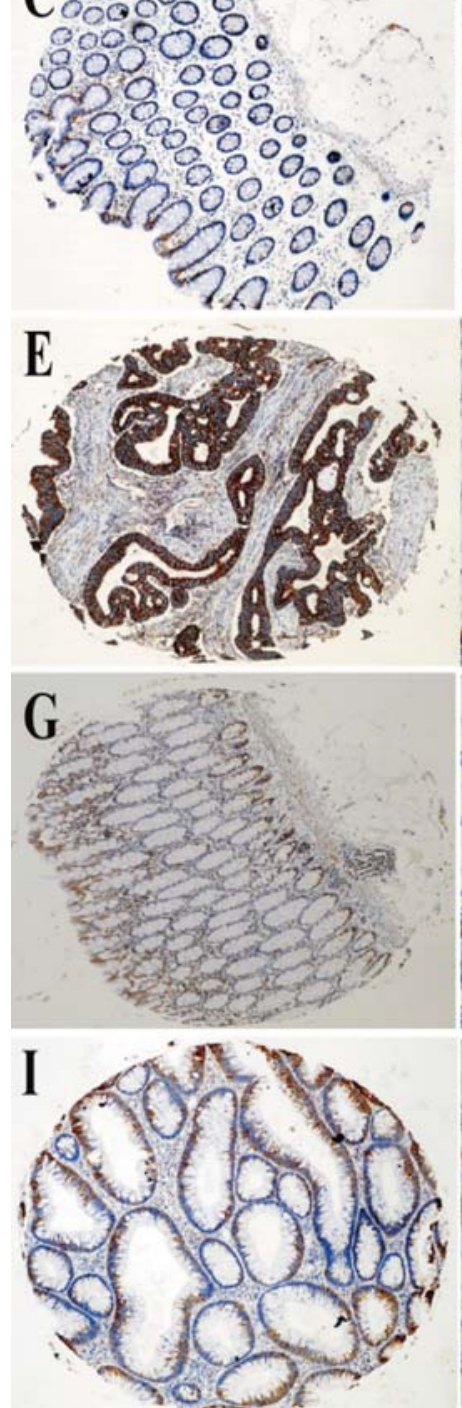
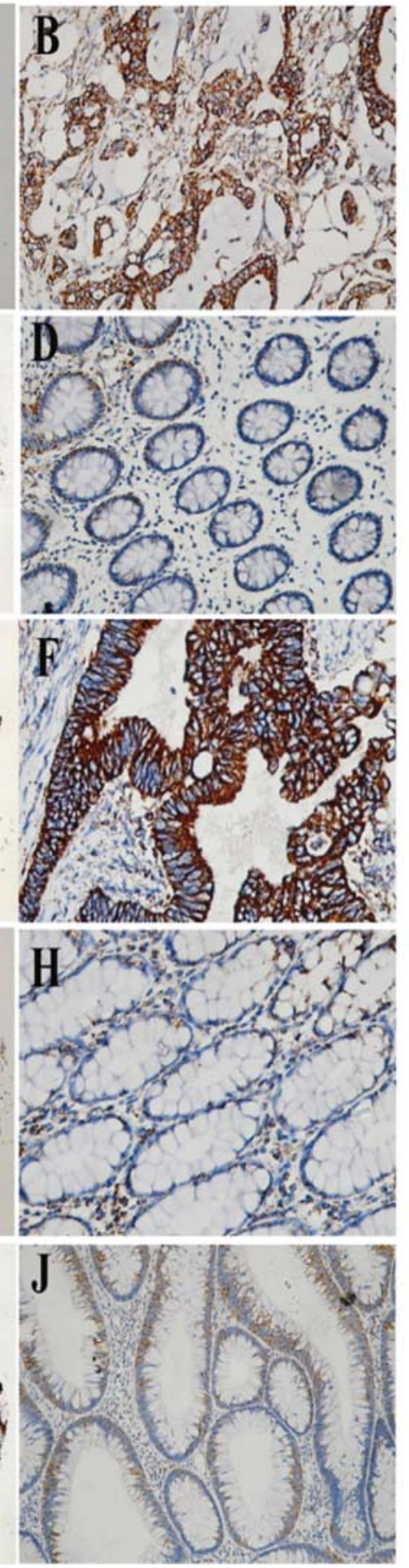

B
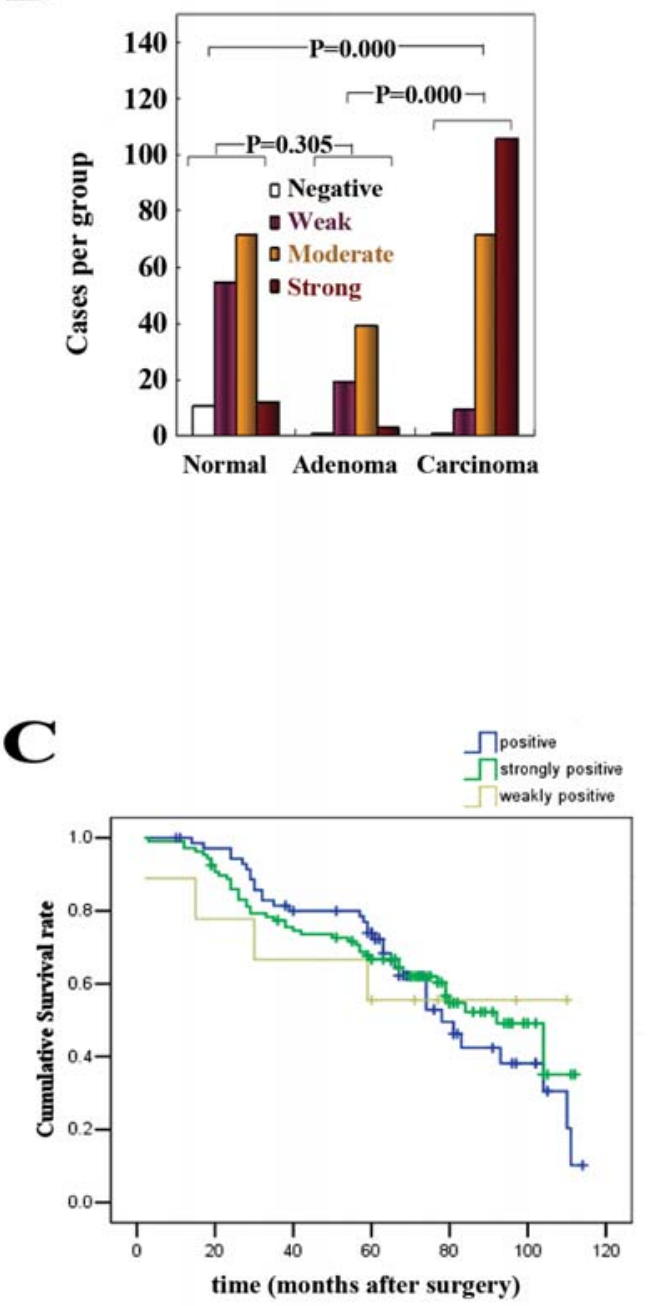

Figure 5. Immunohistochemical analysis of PHB in CRC tissues and related survival analysis. (A) Tissue microarray analysis of the selected targets in CRC. Selected images of CRC tissue microarray elements representing immunohistochemical staining of PHB at different magnifications (x10 and x20) in tumor tissues, normal tissues and adenoma. PHB displayed positive cytoplasmic staining in CRC tissue, and the stain was stronger than in non-neoplastic tissue. The expression of PHB in CRC (A and B; E and F), normal colorectal mucosa (C and D; G and H), and colorectal adenoma (I and J). Images on the left panel were made under magnification x100; the images on the right are magnified images (x200) from the same location depicted at the left. (B) Immunohistochemical staining of 187 specimens from patients with colorectal tumor (adenoma, $\mathrm{n}=62$; carcinoma, $\mathrm{n}=187$ ) and normal colorectal tissue ( $\mathrm{n}=150$ ). The levels of PHB expression were analyzed and compared among the normal colon, colon adenoma, and colon carcinoma tissue specimens $(\mathrm{p}<0.001)$. Other comparisons and p-values are also shown. (C) Kaplan-Meier plot shows no significant correlation between PHB overexression and overall survival of CRC patients.

serum or plasma the microenvironments can, presumably, be comprehensively understood by genomics and proteomics technologies (17). High output proteomics contain more information than individual genomics for analyzing the correlation between differential proteins and malignant tumors (18).

In view of this, we employed proteomics to explore novel biomarkers for CRC. Twelve couples of 2-D patterns of 
Table V. Relevance of differentiation grading to prohibitin immunoreactivity.

\begin{tabular}{lrrrrrr}
\hline Differentiation & Cases & - & + & ++ & $+_{+++^{\mathrm{a}}}$ & Average score $^{\mathrm{b}}$ \\
\hline Well & 51 & 0 & 7 & 35 & 9 & $6.67 \pm 3.05$ \\
Moderate & 104 & 0 & 1 & 20 & 73 & $8.52 \pm 2.93$ \\
Poor & 32 & 0 & 1 & 7 & 34 & $9.62 \pm 3.0$ \\
\hline
\end{tabular}

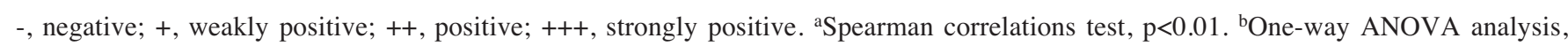
$\mathrm{p}<0.01$; LSD t-test, $\mathrm{p}<0.01$ (well versus moderate, well versus poor, and moderate versus poor).

Table VI. Relevance of UICC staging to prohibitin immunoreactivity.

\begin{tabular}{lcccccc}
\hline UICC staging & Cases & - & + & ++ & +++ & Average score $^{\mathrm{a}}$ \\
\hline I & 27 & 0 & $7.4 \%(2 / 27)$ & $48.1 \%(13 / 27)$ & $25.5 \%(12 / 27)$ & $7.39 \pm 2.75$ \\
II & 79 & 0 & $3.8 \%(3 / 79)$ & $39.2 \%(31 / 79)$ & $57.0 \%(45 / 79)$ & $8.17 \pm 3.058$ \\
III & 81 & 0 & $4.9 \%(4 / 81)$ & $35.4 \%(28 / 81)$ & $60.5 \%(49 / 81)$ & $9.08 \pm 3.539$ \\
\hline
\end{tabular}

-, negative; +, weakly positive; ++, positive; +++, strongly positive. Spearman correlations test, ${ }^{\mathrm{a}} \mathrm{p}=0.226$.

Table VII. Relevance of the location of CRC to Prohibitin immunoreactivity.

\begin{tabular}{lcccccc}
\hline Location & Cases & - & + & ++ & ++ & Average score $^{\mathrm{a}}$ \\
\hline Proximal colon & 31 & 0 & $6.5 \%(2 / 31)$ & $29.0 \%(9 / 31)$ & $64.5 \%(20 / 31)$ & $8.03 \pm 3.07$ \\
Distal colon & 41 & 0 & $7.3 \%(3 / 41)$ & $31.7 \%(13 / 41)$ & $61.0 \%(25 / 41)$ & $8.63 \pm 3.19$ \\
Rectum & 115 & 0 & $3.4 \%(4 / 115)$ & $43.5 \%(50 / 115)$ & $53.1 \%(61 / 115)$ & $8.84 \pm 2.94$ \\
\hline
\end{tabular}

-, negative; +, weakly positive; ++ , positive; +++ , strongly positive. Rank-sum test, ${ }^{\mathrm{a}} \mathrm{p}=0.584$.

protein expression were obtained in the present study with $985 \pm 45$ and $1012 \pm 53$ spots detected in the carcinomas and normal tissues. Forty differentially expressed protein spots in the carcinoma were selected for study. The 40 differentially expressed protein spots were identified by MS. After analysis and classification of these proteins, 35 distinct proteins were differentially expressed at least 2-fold, including 17 upregulated and 18 down-regulated proteins. Among these, we focused on $\mathrm{PHB}$, which was found overxpressed in ten of twelve cases of CRC. For both the function and potential role of PHB in colorectal carcinoma tumorigenesis or progression is not yet well understood, it is necessary to further assess the potential of this protein as a CRC biomarker.

PHB is a highly conserved protein with diverse functions in eukaryotic cells; such as, suppressing growth of tumor, regulating cell proliferation, and anti-infection and antiinflammation (8). It has been reported that the PHB proteins can co-localize with Rb, and they can suppress E2F-mediated transcription and cell growth $(19,20)$. In addition, PHB also can induce p53-mediated transcription by enhancing its recruitment to promoters (7).

PHB has been regarded as a negative regulator of cell proliferation, which suggested it was a suppressor gene (5-8). However, the role of PHB in tumor development and progression is controversial and PHB may not always inhibit cancer development (21). Overexpression of PHB was observed in breast cancer cell lines (22), osteosarcoma cells (23), bladder carcinomas (9), ovarian tumors $(24,25)$, and gastric carcinoma (26). Mengwasser et al reported that the expression levels of serum of PHB in colorectal cancer patients was higher than in normal control subjects (27).

In the present study we also observed the overexpression of PHB in CRC tissue, which was consistent to the study of Mengwasser et al. We speculate it was due to PHB's role as a transcriptional regulator, and mitochondrial chaperone (27). Generally, the expression of suppressor proteins in tumor cells are down-regulated, such as with the p53 protein. However, it may also be that the expression does not change 
but there are gene mutations, such as with the PTEN gene (28). In the present study we found enhanced expression of PHB in CRC samples, which was contradictory to PHB functioning as a tumor suppressor protein. There are some theories that may explain this contradiction. PHB is a mitochondrial molecular chaperone that affects stability of new codogenic proteins, and subsequent assembly of the respiratory chain complex that indirectly regulates cell senescence and carcinogensis. Thus, we suppose that the level of PHB is constantly reduced during the process of cell senescence, and that PHB gene knockout can accelerate the senescence. On the contrary, the overexpression of PHB protein will prolong cell survival (29). Nijtmans et al (30) proposed another hypothesis, that enhanced oncoprotein Myc expression induced the up-regulation of PHB protein via a connection between a regulatory element in the $\mathrm{PHB}$ promoter and Myc. Meanwhile, the induction also induces the expressions of glycolytic enzymes and transport proteins in glycometabolism. This increases anaerobic zymolysis and attenuates aerobic oxidation, which is consistent with the increased anaerobic zymolysis in tumor cells; very crucial events in the establishment of the early stages of tumor cell lines.

Western blot and immunohistochemistry assays showed increased expression of PHB in CRC tissues. However, PHB levels were not significantly up-regulated in non-malignant colorectal adenoma, although the expression was increased in the normal-adenoma-carcinoma sequence of CRC development.

Carcinogenesis in sporadic CRC has been comprehensively studied and regarded as a multi-step process; with each step representing specific gene mutations or epigenetic changes. (31). The accumulation of genetic mutations and epigenetic alterations involving oncogene activation and tumor suppressor gene inactivation accelerates the pathological progression from adenoma to sporadic CRC (32). Several genes play a dominant role in the evolution of the adenoma-carcinoma sequence. During this transition, adenoma size, the degree of dysplasia, and the presence of villous histology were increased. Other alternations present include induction of the $\mathrm{K}$-ras oncogene and loss of function of tumor suppressor genes on chromosome $18 \mathrm{q}$ in the region of the deleted gene in colon cancer (DCC). The PHB gene is located on the long arm of chromosome-17 where allelic losses in human sporadic CRC are very frequent (33). Overexpression of the PHB protein was significant in CRC as compared with adenomas and normal colon tissues, which suggested a possibility that PHB expression may be more intimately involved in the initial development, not in the later progression of CRC.

To clarify the potential role of PHB as a biomarker in the progression, prognosis, or aggressive behavior of CRC, we investigated the correlation between PHB expression in CRC and related clinical pathological parameters. The increase in PHB protein concentration corresponded to the differentiation degree of colorectal carcinoma. A significant increase was detected in poorly differentiated colorectal carcinoma tissue compared to moderately and well differentiated colorectal cancer tissue $(\mathrm{p}<0.01)$. However, the results showed no significant correlation between PHB overexpression and sex, age, pathological histological type, as well as different tumor staging. The survival analysis also suggested no significant correlation between PHB overexpression and the survival rate. We speculate that $\mathrm{PHB}$ might be associated with the transformation process from adenoma to $\mathrm{CRC}$, and it will be helpful for the diagnosis of CRC.

In conclusion, new molecular insights into the initiation of $\mathrm{CRC}$ will give more useful clues to the early detection, possible prevention of neoplasia, and potential targets for early therapy. The data suggested that PHB protein could be a putative diagnostic and differentiational biomarker for tissue-based detection of colorectal carcinoma.

\section{Acknowledgments}

This work was supported by a grant from the Fujian Medical University Non-state-run Affiliated Hospital Medical Science and Technique Foundation (FZS08006), Quanzhou Science and Technology key program (2009Z31).

\section{References}

1. Weitz J, Koch M, Debus J, Hohler T, Galle PR and Buchler MW: Colorectal cancer. Lancet 365: 153-165, 2005.

2. He YJ, Wu YZ, Mou ZR, et al: Proteomics-based identification of hsp60 as a tumor-associated antigen in colorectal cancer. Proteomics Clin Appl 1: 336-342, 2007.

3. Leman ES, Schoen RE, Magheli A, Sokoll LJ, Chan DW and Getzenberg RH: Evaluation of colon cancer-specific antigen 2 as a potential serum marker for colorectal cancer. Clin Cancer Res 14: 1349-1354, 2008.

4. Thierolf M, Hagmann ML, Pfeffer M, et al: Towards a comprehensive proteome of normal and malignant human colon tissue by 2 -d-lc-esi-ms and 2-de proteomics and identification of s100a12 as potential cancer biomarker. Proteomics Clin Appl 2: 11-22, 2008.

5. Sato T, Saito H, Swensen J, et al: The human prohibitin gene located on chromosome $17 \mathrm{q} 21$ is mutated in sporadic breast cancer. Cancer Res 52: 1643-1646, 1992.

6. Jupe ER, Liu XT, Kiehlbauch JL, McClung JK and Dell'Orco RT: Prohibitin in breast cancer cell lines: loss of antiproliferative activity is linked to 3 ' untranslated region mutations. Cell Growth Differ 7: 871-878, 1996.

7. Fusaro G, Dasgupta P, Rastogi S, Joshi B and Chellappan S: Prohibitin induces the transcriptional activity of p53 and is exported from the nucleus upon apoptotic signaling. J Biol Chem 278: 47853-47861, 2003.

8. Mishra S, Murphy LC, Nyomba BLG and Murphy LJ: Prohibitin: a potential target for new therapeutics. Trends Mol Med 11: 192-197, 2005.

9. Asamoto M and Cohen SM: Prohibitin gene is overexpressed but not mutated in rat bladder carcinomas and cell-lines. Cancer Lett 83: 201-207, 1994.

10. Coates PJ, Nenutil R, McGregor A, et al: Mammalian prohibitin proteins respond to mitochondrial stress and decrease during cellular senescence. Exp Cell Res 265: 262-273, 2001.

11. Roblick UJ, Hirschberg D, Habermann JK, et al: Sequential proteome alterations during genesis and progression of colon cancer. Cell Mol Life Sci 61: 1246-1255, 2004.

12. Stulik J, Hernychova L, Porkertova S, et al: Proteome study of colorectal carcinogenesis. Electrophoresis 22: 3019-3025, 2001.

13. Li X, Zhuang Z, Liu J, Huang H, Wei Q and Yang X: Proteomic analysis to identify the cellular responses induced by hydroquinone in human embryonic lung fibroblasts. Toxicol Mech Methods 16: 1-6, 2006.

14. Cheng J, Yang J, Xia Y, Karin M and Su B: Synergistic interaction of mek kinase 2, c-jun n-terminal kinase (jnk) kinase 2, and jnk1 results in efficient and specific jnk1 activation. Mol Cell Biol 20: 2334-2342, 2000.

15. Kreisberg JI, Malik SN, Prihoda TJ, et al: Phosphorylation of akt (ser473) is an excellent predictor of poor clinical outcome in prostate cancer. Cancer Res 64: 5232-5236, 2004. 
16. Feng YZ, Shiozawa T, Miyamoto T, et al: Overexpression of hedgehog signaling molecules and its involvement in the proliferation of endometrial carcinoma cells. Clin Cancer Res 13: 1389-1398, 2007.

17. Cho WCS: Contribution of oncoproteomics to cancer biomarker discovery. Mol Cancer 6: 2007.

18. Petricoin EF, Zoon KC, Kohn EC, Barrett JC and Liotta LA: Clinical proteomics: translating benchside promise into bedside reality. Nat Rev Drug Discov 1: 683-695, 2002.

19. Wang S, Nath N, Adlam M and Chellappan S: Prohibitin, a potential tumor suppressor, interacts with $\mathrm{rb}$ and regulates e $2 \mathrm{f}$ function. Oncogene 18: 3501-3510, 1999.

20. Fusaro G, Wang S and Chellappan S: Differential regulation of rb family proteins and prohibitin during camptothecin-induced apoptosis. Oncogene 21: 4539-4548, 2002.

21. Czarnecka AM, Campanella C, Zummo G and Cappello F: Mitochondrial chaperones in cancer: from molecular biology to clinical diagnostics. Cancer Biol Ther 5: 714-720, 2006.

22. Williams K, Chubb C, Huberman E and Giometti CS: Analysis of differential protein expression in normal and neoplastic human breast epithelial cell lines. Electrophoresis 19: 333-343, 1998.

23. Fellenberg J, Dechant MJ, Ewerbeck V and Mau H: Identification of drug-regulated genes in osteosarcoma cells. Int J Cancer 105: 636-643, 2003

24. Cliby W, Sarkar G, Ritland SR, Hartmann L, Podratz KC and Jenkins RB: Absence of prohibitin gene mutations in human epithelial ovarian tumors. Gynecol Oncol 50: 34-37, 1993.

25. Wang L, Zhu YF, Guo XJ, et al: A two-dimensional electrophoresis reference map of human ovary. J Mol Med 83: 812-821, 2005 .
26. Kang XD, Zhang L, Sun J, et al: Prohibitin: a potential biomarker for tissue-based detection of gastric cancer. J Gastroenterol 43: 618-625, 2008.

27. Mengwasser J, Piau A, Schlag P and Sleeman JP: Differential immunization identifies phb $1 / \mathrm{phb} 2$ as blood-borne tumor antigens. Oncogene 23: 7430-7435, 2004.

28. Lynch ED, Ostermeyer EA, Lee MK, et al: Inherited mutations in PTEN that are associated with breast cancer, cowden disease, and juvenile polyposis. Am J Hum Genet 61: 1254$1260,1997$.

29. Tsai HW, Chow NH, Lin CP, Chan SH, Chou CY and Ho CL: The significance of prohibitin and c-met/hepatocyte growth factor receptor in the progression of cervical adenocarcinoma. Hum Pathol 37: 198-204, 2006.

30. Nijtmans LG, Artal SM, Grivell LA and Coates PJ: The mitochondrial phb complex: Roles in mitochondrial respiratory complex assembly, ageing and degenerative disease. Cell Mol Life Sci 59: 143-155, 2002.

31. Kondo Y and Issa JP: Epigenetic changes in colorectal cancer. Cancer Metastasis Rev 23: 29-39, 2004.

32. Vogelstein B, Fearon ER, Hamilton SR, et al: Genetic alterations during colorectal-tumor development. N Engl J Med 319: 525-532, 1988

33. Leggett B, Young J, Buttenshaw R, et al: Colorectal carcinomas show frequent allelic loss on the long arm of chromosome 17 with evidence for a specific target region. Br J Cancer 71: 1070-1073, 1995. 